\title{
Creative Approaches to Teaching Graduate Research Methods Workshops
}

\author{
Best practice article \\ Peter Reilly \\ University of Limerick
}

\begin{abstract}
Engagement and deeper learning were enhanced by developing several innovative teaching strategies delivered in Research Methods workshops to Graduate Business Students. Focusing primarily on students adopting a creative approach to formulating a valid research question for undertaking a dissertation successfully. These techniques are applicable to most subject domains to ensure student engagement. Addressing the various multiple intelligences and learning styles existing within groups while ensuring these sessions are student centred and conducive to a collaborative learning environment. Blogs, interactive tutorials, online videos, games and posters, are used to develop student's cognitive and metacognitive abilities. Using novelty images appeals to a groups' intellectual curiosity, acting as an interpretive device to explain the value of adopting a holistic rather than analytic approach towards a topic.
\end{abstract}

Keywords: Creativity, deeper learning, play, graduates, information literacy, teaching, engagement, metacognition

\section{Contact:}

Peter Reilly

University of Limerick, Glucksman Library, Librarian

Kemmy Business School, Limerick, Ireland

e-mail: peter.reilly@ul.ie 


\section{Introduction}

Students are already being creative in the way they use and manage knowledge to conduct research, complete assignments and collaborate on projects. It seems a natural progression to integrate a creative teaching strategy in workshops to stimulate their intellectual curiosity and engage them. Learning will only occur successfully if creativity is encouraged by an individual being curious in the first place (Hensley, 2004). Play is essential to creative teaching, and is introduced into sessions via team based games, ensuring, motivation, engagement and deeper learning (Torrance, 1981). Enabling students to explore, take risks with their learning by collaborating in groups while undertaking novel discovery tasks. Participating in these activities compels individuals to step out of their comfort zone to solve problems and adopt a creative approach. They embrace these learning risks by experimenting in a safe play environment and realise the perceived threat is more terrifying than the actuality itself (Beck, 1992). While being alert to the potential hazards and insecurities involved in undertaking a dissertation, using both their knowledge and creativity to avoid them. Creativity requires individuals to possess a deep knowledge of their own discipline, before attempting to improve it. Similar to the process a student undertakes in conducting a literature review of their chosen topic, to develop a valid research question.

The overall performance of an individual can be improved by ensuring the matching of the correct teaching techniques with his/her personal cognitive style. Employing a combination of text and visual based resources appeals to the multiple intelligences residing within a group. Knowledge Management and the Six Ds of Solution fluency are two techniques which provide contrasting perspectives for conducting a research strategy. They both emphasise the importance of adopting a holistic approach, and are explored in more detail in the case study. Applying creativity in my workshops ensures a student centred collaborative learning environment among adult learners, who undertake a series of novel discovery tasks. Exploring this concept further reveals an enigma, and to gain a better understanding I have interpreted it from both a psychological and problem solving perspective.

To integrate creativity effectively in a session we must first understand what the concept actually means. This involves reviewing it in terms of current educational policy and whether it is already embedded within university curriculums. While recognising that continuous professional development by graduates ensures they remain competent in a constantly evolving labour market. The contributory role organizational culture plays in the creation of an innovative work environment is also assessed. In relation to learning theory certain aspects of cognitive psychology are probed particularly the unique set of skills each individual develops in order to think and learn.

\section{Educational Policy}

Creativity is universally recognised by the Higher Education sector as a core skill students require in order to succeed in the modern world. Only recently several policy documents and reports including NMC Horizon, Educause, and the European Union emphasise its importance. Employers are seeking staff who are collaborative, articulate, can solve problems, and think critically, which are key components of being creative. A recent European Union report on improving the quality of university teaching acknowledges it 
needs to simultaneously encourage deeper learning, and be aligned with the requirements of industry. Students need to be able to engage with problems which are relevant to them, bigger than their courses and make a significant contribution to society (McAleese, 2013). They should follow their intellectual passions which intrinsically motivates them and ultimately are more rewarding and fulfilling. Universities recognise the importance of integrating creativity within the curriculum because it encourages the student to adopt a holistic approach to a discipline. As we shall see creativity engages, encourages complex thinking, and fosters collaboration which all contribute to deeper learning. A recent Educause paper identified key cognitive strategies students require in order to succeed, including the ability to hypothesize, analyse, strategize and evaluate (Venezia, 2014). Most colleges have developed similar sets of generic graduate skills applicable to any future work environment. The cognitive psychologist Jerome Bruner (1962) recognised that as the future was so difficult to define, creativity was the best tool to prepare both our children and students for evolutionary change (Runco, 2004).

\section{Employers and Organizational Culture}

It is worth remembering that creativity is not unique to certain individuals but a skill everyone can develop which requires passion and feelings. A person simply has to discover their medium to realise their true potential and master it, by developing a good work routine (Tharp, 2003). The demands of the modern workplace are constantly evolving mainly in response to advances in technology. Consequently students today require a set of generic skills as epitomised by the graduate attributes in order to succeed in this competitive environment. Firms expect new recruits to possess a specific set of skills obtained through informal learning rather than more formal structures. This type of learning called self-directed, happens outside classroom environments and is aligned with the students' own personal learning goals (Johnson, L., Adams Becker, S., Cummins, M., Estrada, V., Freeman, A., Ludgate, \& Austin, 2013). On entering the labour market graduates emphasize their distinctiveness to recruiters by promoting their individual achievements, work experience, relevant qualifications and mobility (Beck, 1992). Interpreting this market from the employer's perspective, reveals there is a shortage of exceptional graduate talent from which they can draw upon. They are seeking new hires who can both identify problems and solve them. The focus is on lifelong learning with employees constantly upskilling to become competent with new technologies and tasks. Companies consider this type of learning as an essential strategic component to developing talent at senior management levels (Robinson, 2001).

Modern organizations are techno human systems composed of both human emotions and rational thinking, which dictates their overall performance. Emotions play a significant role and determine staff engagement in terms of collaboration, productivity and happiness. Aesthetics can be used to develop a pleasant physical environment appealing to the senses, which both inspires creativity and ensures happy emotions (Schiuma, 2014). Employees are encouraged to view collaborating in teams as creative opportunities, to participate in cross departmental or divisional projects with specific objectives. Several commentators acknowledge the most creative teams contain individuals with different areas of expertise, levels of experience, capable of generating a flow of realistic and tangible ideas (Piirto, 2011; Robinson, 2001). This collaborative culture contributes to greater knowledge sharing between staff and managers who learn from each other, resulting in the breaking down of some existing hierarchical structures. 
A more fluid organizational structure provides additional learning opportunities which fosters greater innovation leading to improved firm performance overall (López, 2004).

Employees who are given responsibility for managing large projects only learn through practical experience the risks these involve, and acquire the relevant knowledge to minimise them. Their creative abilities are tested in these situations while providing an opportunity for their unrealised potential to emerge. As a result they are more confident to pursue novel and innovative ideas, because feel supported by management. Another major contributing factor to maintaining an individual's intrinsic motivation in work is their social environment which drives his/her creativity at a particular time (Amabile, 1997). In contrast where creativity is not supported or normalised as part of the organisational culture, individuals are inclined to internalise their creative ideas, because afraid to share them with others (Deverell \& Moore, 2014).

Creativity will only thrive in organizations, providing the necessary conditions already exist to facilitate people who are passionate about their work which matches both their skills and expertise. Within these environments individuals are encouraged to adapt to change, approach problems holistically and achieve their goals through group consensus (Barczak et al, 2010). To energise an entire firm involves creating an atmosphere whereby risk is encouraged, playing with ideas is acceptable and failure is perceived as part of the learning process. Management must align the value of creative abilities with the overall objectives of the organization for this culture to prosper (Robinson, 2001).

\section{Cognitive Psychology of Learning Theory}

Exploring creativity in terms of learning theory involves discussing it briefly from a cognitive psychology perspective, particularly in relation to Cognitive Style and Dual Coding Theory. Cognitive Style Analysis (CSA) is concerned with the unique set of skills, techniques, preferences and behaviour each individual develops in order to think and learn during a process of lifelong learning. Their overall performance is determined by their own self-perception as a learner and individual motivation to succeed (Riding \& Rayner, 2000). Various theoretical cognitive style models exist but "Dual Coding Theory" is the most relevant in terms of creativity. Today we live in an image dominated society, with even "Big Data" being presented visually as a means to understanding it better. Sometimes pictures are the only outlet to express a vague thought sequence which is impossible to convey through words (Robinson, 2001). 


\begin{tabular}{|l|l|l|l|}
\hline Theorist & $\begin{array}{l}\text { Models \& } \\
\text { Frameworks }\end{array}$ & \multicolumn{1}{|c|}{ Results } & \multicolumn{1}{|c|}{ Summary } \\
\hline Paivio (1979) & Dual Coding Theory & $\begin{array}{l}\text { Visual learners } \\
\text { Verbal learners }\end{array}$ & $\begin{array}{l}\text { Processes } \\
\text { information in } \\
\text { terms of images or } \\
\text { text }\end{array}$ \\
\hline $\begin{array}{l}\text { Riding \& Cheema } \\
(1991)\end{array}$ & $\begin{array}{l}\text { Cognitive Style } \\
\text { Analysis Theory }\end{array}$ & $\begin{array}{l}\text { Wholist - Analytic } \\
\text { Verbaliser - Imager }\end{array}$ & $\begin{array}{l}\text { Examines the } \\
\text { whole picture or } \\
\text { specific parts }\end{array}$ \\
\hline $\begin{array}{l}\text { Rayner \& Riding } \\
(1997)\end{array}$ & $\begin{array}{l}\text { Cognitive Style } \\
\text { Analysis model }\end{array}$ & $\begin{array}{l}\text { Identifies an } \\
\text { individual's } \\
\text { learning } \\
\text { preferences }\end{array}$ & $\begin{array}{l}\text { Computerised } \\
\text { model measuring } \\
\text { individual learning } \\
\text { preference }\end{array}$ \\
\hline Kaufmann (1989) & $\begin{array}{l}\text { Assimilator Explorer } \\
\text { Model }\end{array}$ & $\begin{array}{l}\text { Assimilators } \\
\text { Explorers }\end{array}$ & $\begin{array}{l}\text { Two different } \\
\text { approaches to } \\
\text { cognitive problem } \\
\text { solving }\end{array}$ \\
\hline
\end{tabular}

Table 1. Cognitive Style Analysis Theories Related to Creativity.

Dual Coding Theory developed by the Canadian Allan Paivio (1979) postulated that learners process information either visually or verbally. He concluded that knowledge presented visually is easier for individuals to recall from memory because the images are spatially organised, compared to language which is stored in a sequence and takes longer to retrieve. This work was further developed in subsequent research conducted by Riding and Cheema (1991) in which they analysed all the previous existing cognitive style theories and synthesised them into two fundamental categories Wholist- Analytic and Verbaliser -Imager. Their "Cognitive Style Analysis" (CSA) Theory argued that people first process information by either looking at the whole picture or viewing it in parts. Subsequently thinking about it mentally in terms of images or text. This culminated in Rayner and Riding (1997) developing a "Cognitive Style Analysis Model" a computerised measure which identifies an individual's learning preference. One of these styles applicable to creativity is the Assimilator Explorer model involving two different approaches to undertaking problem solving tasks.

Assimilators have a preference for following the rules whereas Explorers are curious by nature and enjoy novelty. Creativity encompasses a combination of elements from both of these styles in order for it to be complete (Martinsen \& Kaufmann, 2000). I think the "Theory of Achievement Motivation" as developed by McClelland, Atkinson, Clark, and Lowell (1953) is also applicable in the creative context. It describes human behaviour when dealing with uncertainty and in predicting the difficulty of a task or problem. These include the risks an individual is prepared to take, their own persistence and level of performance. Which is all determined by two distinct factors, an individual's motive to succeed, and to avoid failure. In the next section the concept of creativity is explored in greater depth, particularly why creative individuals are risk takers and intrinsically motivated to succeed. 


\section{Review of Creativity Literature}

Creativity is an ambiguous term which is discussed in many contexts and usually associated with motivation, innovation and problem solving. It is not domain specific and is a process which involves gaining a deep knowledge of a particular subject. It is tied up with human behaviour, individual motivation and as a mechanism for adapting to change. In fact Bruner (1962), discussing it in the artistic sense, defines the value of the creative act as an extension of the individual self, with the purpose to produce effective surprise from the human condition of the beholder. This mirrors my own experience of conducting workshops with the focus being student engagement. He contended creative people interpret the world differently and their intention is to produce provocative work which distinguishes it from banality. This reflects his own elitist vision for education which should focus on developing a process of intelligence, enabling individuals to rise above the norms of society, to be innovative and develop their own world. As discussed earlier everyone possesses creative strengths which only truly emerge once they discover their medium to work with.

Another lens in which to approach creativity is to view it in terms of problem solving which involves a novelty aspect. A creative individual is capable of re framing or formulating the problem to make it more manageable. According to the philosopher and scientist Michael Polanyi (1958), the ability to identify a problem and realise it can be solved, makes a contribution to knowledge itself. The heuristic principle of doubt plays an integral part in the creative process because it goes against accepted belief by recognising something is wrong within a discipline which leads to a new discovery (Csikszentmihalyi, 1996; Polanyi, 1958). A problem only becomes a burden to an individual if it begins to worry them. This resulting anxiety intrinsically motivates them to try solve the puzzle and only becomes a discovery by relieving them from this particular burden. Creative individuals possess the ability to seamlessly shift between conventional and unconventional thought processes depending upon whichever is more suitable at the time. They can instantly distinguish good ideas from bad and avoid time wasting (Csikszentmihalyi, 1996). Another characteristic is their ability to lead, inspire, motivate and influence others by promoting their own ideas as common objectives. Ensuring the advancement of knowledge within a discipline by steering it in the direction it needs to go They embrace these learning risks by experimenting in a safe play environment and realise the perceived threat is more terrifying than the actuality itself (Beck, 1992); Sternberg, 2006).

Polanyi (1958) identifies creativity as the logical gap between the obstacle to overcoming a problem and the process of illumination when it is crossed. According to Bruner (1962) the constant practising of problem solving and figuring out puzzles ensures that memory can be conserved rather than lost. Creative problem solving involves constant experimentation and revision to achieve the intended, outcome and the longer you can leave your options open the more original and suitable the solution will be. A field will only generate novelty for an individual when there is convergence between their intellectual ability (intelligence) to cope with the problem and recognising the instability already existing within it. One of the most enjoyable experiences any human can engage with is the process of playing with ideas resulting in the discovery of something new. Eventually these thoughts flow beyond the boundaries of what is already known and percolate undiscovered terrain (Csikszentmihalyi, 1990). This incubation period commences when the task is set aside, and the person engages in another activity, while the subconscious still works on the problem. A prime example being "Picture This" one 
of the games I use in workshops to explain the importance of adopting a holistic approach to a research topic. Encountering it for the first time I realised its potential, but was unsure how to actually implement it in a workshop, which took a further six months to resolve. I set this problem aside and subsequently my subconscious worked on it.

\section{Intelligence and Consciousness}

Exploring how human consciousness operates, reveals it cannot be biologically controlled by the body, but instead serves as a filter for interpreting the external environment around it. Consequently the information permitted access, is processed and evaluated thoroughly before being relayed to the body as commands to execute. This information allowed into consciousness is extremely important, because it determines both the content and quality of an individual's life (Csikszentmihalyi, 1990). The concept of intelligence as existing in a state of discontinuity, in order to both understand itself and life, was first proposed by the French Philosopher Henri Bergson (1998) writing about evolution at the beginning of the $20^{\text {th }}$ Century. It could only make sense of the world by bringing non related immobile forms together in order to construct new meaning from them.

Similarly many intellectual breakthroughs have been achieved by taking something from one specific domain, applying it to another to revitalize it and create something new. In the field of "Artificial Intelligence", research conducted by Langley and Jones, (1988) into developing a theory of "scientific insight", recognised that creativity involves more than simple retrieval and the application of old ideas to new situations. They focused specifically on the importance of reasoning through analogy which allows knowledge to be used in new ways.(Runco \& Chand, 1995). Today computers are being taught the ability to interpret data in order to write sports and business journalism as the following example illustrates.

A research project "News at Seven" conducted by faculty and students within the Artificial Intelligence Labs at Northwestern University involved creating a system which could present the results of an online search query as a narrative argument. A subsequent collaboration with the Medhilll School of Journalism resulted in the creation of a commercial company. Now just one of several companies providing bespoke data driven reporting services to large sports networks and business publishers (Adams, 2015).

Learning involves the student trying to comprehend their own environment by cognitively processing information internally and combining prior experiences to synthesise new knowledge. One commentator interpreted knowledge as being a model we construct in order to give both meaning and structure to the regularities in experience (Bruner, 1962). Knowledge itself is composed of two distinct types declarative and procedural which are both essential to creativity. Declarative concerns knowing facts about something, and can either aid or hinder creative thought depending on the particular domain (Runco \& Chand, 1995). The focus of my workshops are to develop a student's procedural knowledge which encourages strategic thinking, by following a set of instructions to complete a task. Ensuring engagement and deeper learning, by enabling them with the skills and confidence to apply creative thinking to their own individual research process. Polanyi, (1958) defines these personal learning moments of deep contemplation in terms of intellectual passions, whereby an individual is intrinsically motivated and totally immersed in the actual experience of completing a task.

It is a precursor to the Flow concept, an automatic state of highly focused concentration which an individual embarks on when deeply engaged in an activity. This 
can only occur when the activity is complex providing new challenges resulting in both personal and cultural growth (Csikszentmihalyi, 1996). During this stage of the creative process the individual becomes intrinsically motivated, and is at his/her most productive, forgetting about time or meals. Outlined below are the nine characteristics as identified by Csikszentmihalyi (1990) which must exist in order for the flow process to happen.

1. Clearly defined set of goals for each step of the way

2. There is immediate feedback to one's actions

3. There is a balance between challenges and skills

4. Action and awareness are merged

5. Distractions are excluded from consciousness

6. There is no worry of failure

7. Self-consciousness disappears

8. Sense of time becomes distorted

9. An activity become autotelic

This sense of intellectual curiosity encourages the continuous testing, experimentation, and revision of the creative problem solving until a satisfactory outcome is achieved. The most appropriate solution can be obtained, once there are no time limits imposed on the choices available. In some cases it can take years for certain activities to achieve a satisfactory outcome. The importance of goals and feedback are an integral part of this process. The case study in next section explores how it is applicable to the educational context.

\section{Case Study - Applying Creativity in an Educational Context}

As discussed previously in the Literature Review, creativity involves any novel act, idea, or product which transforms an existing domain, or applied to another one revitalises it, resulting in something new (Csikszentmihalyi, 1990). This can only happen if an individual is curious and intrinsically motivated to engage with a subject at a deeper level. At the heart of successful teaching and learning encounters are curious and creative students who recognise the value of information and how it contributes to the creation of new knowledge (Hensley, 2004). The following case study explores some of the creative techniques I use to engage students. Essentially I am trying to stimulate their intellectual curiosity which contributes to self-directed learning. The purpose of these collaborative activities are to encourage a sense of play by removing any inhibitions and facilitating a flow process. While developing the group's cognitive skills as a precursor to devising a research strategy.

Interpreting creativity through a problem solving lens, reveals the student's problem is selecting the appropriate technique for conducting a literature review, to develop a valid research question. This problem becomes more manageable once they realise it is cross disciplinary and adopt a holistic rather than an analytic approach towards the topic. One way of engaging and clarifying this problem is encouraging them to apply the principles of Knowledge Management. Particularly Harold Jarche's Personal Knowledge Mastery (PKM) theoretical framework called "seek sense share" outlined in one of his blog posts (Jarche, 2014). I believe it is very relevant to explaining the research process. Emphasising to students that undertaking a dissertation successfully consists of each of these three stages. I show a visual representations of his theory created by other members of his professional network as noted in Figure 1. (Chua, 2014) 


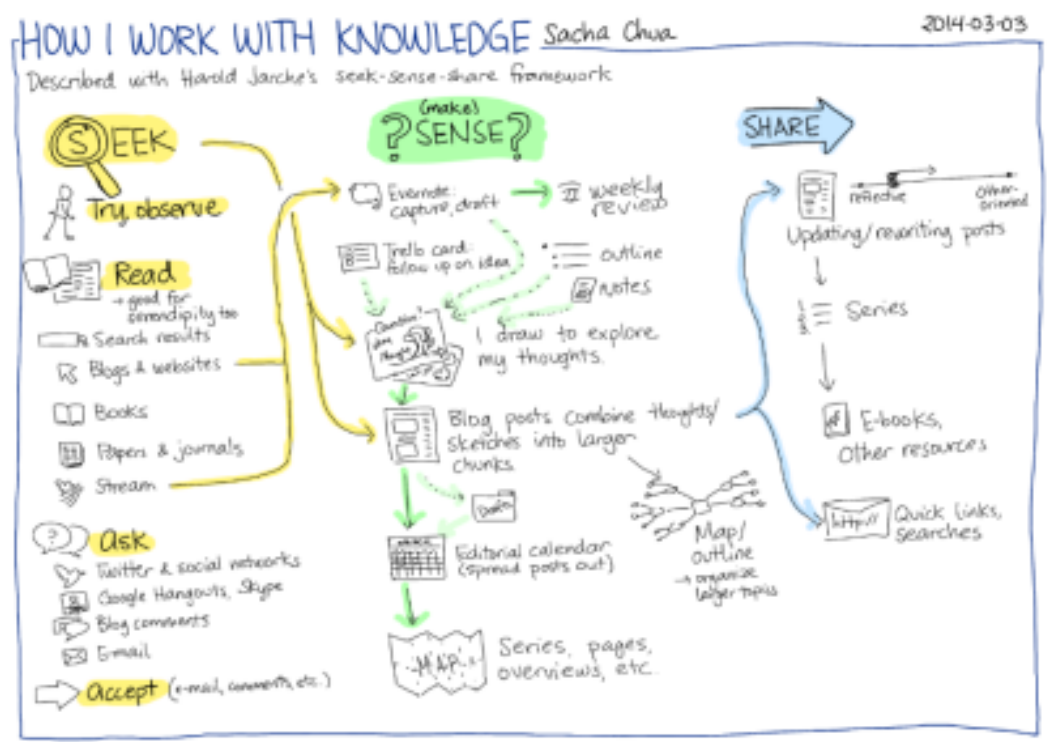

Figure 1. Visual presentation of the Seek Sense Share model created by Sacha Chua. Students really engage, because it is easy to follow, and can relate it to their own literature review.

Contrasting this technique is Solution Fluency another creative approach to problem solving developed by the Global Digital Citizen Foundation (2015) which is applicable to the research context. This six step process known as the "6 Ds" is very popular with students due to its simplicity.

1. Define

2. Discover

3. Dream

4. Design

5. Deliver

6. Debrief

I encourage students to consider it as another lens in which to approach their dissertation topic. They have the option to view either an online video outlining the process or a poster of it. These techniques encapsulate Charles Leadbeater's (2010), TED talk discussing learning innovation in the developing world and the lessons for western educators. The main tenets of his argument are that students need to be engaged before teaching them, and learning has to be productive in order to make sense. These are the very reasons I apply creativity to my own workshops.

\section{Repurposing Childrens' Games as Reflective Tools}

Games are a simple technique to engage students, because they empower, motivate and inform them. Providing an element of both humour and fun, which causes "effective surprise" among participants because they are not expecting it from this session. The curious thing about "effective surprise" is that, it provokes a reaction by occurring in ordinary situations or things and is not rare, infrequent, or bizarre (Bruner, 1962). Stop the Bus is a child's literacy game which I have repurposed as a reflective tool for adults to encourage collaboration, motivation, and metacognition. This team based activity contains an appropriate level of challenges and skills, ensuring they feel confident enough to complete it and become deeply engaged. A consensus is achieved among each 
individual group by engaging in a process of internal dialogue to devise a solution for each problem.

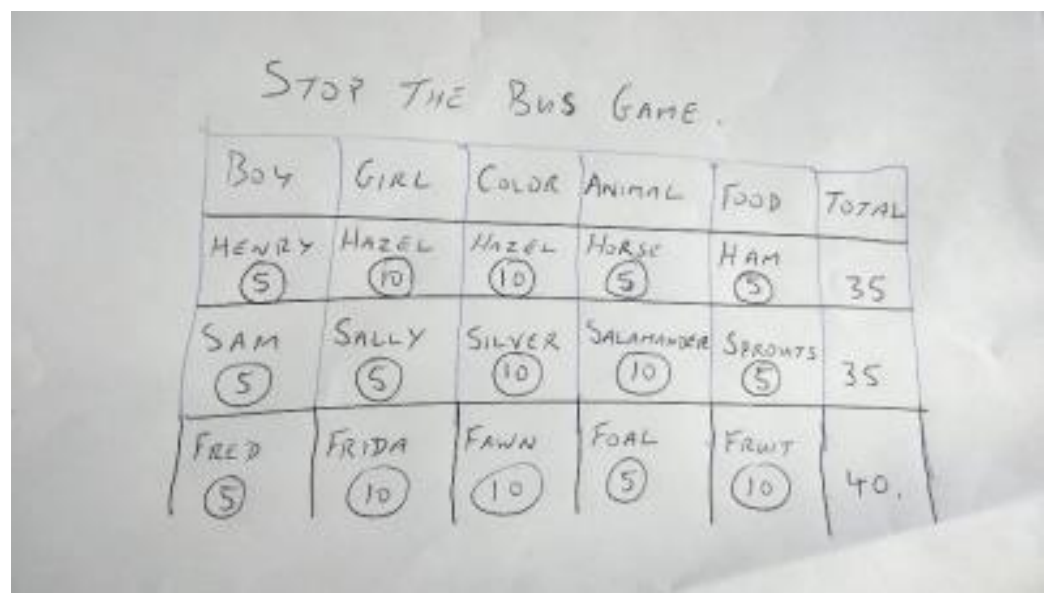

Figure 2. Stop the Bus Game Sheet.

I explain to the group the simple rules of this name game, and one person is chosen to start mentally reciting the alphabet. After several seconds s/he is told to stop and whatever letter they have selected is used in the game. Each team nominates a scribe to write down with pen and paper a name beginning with the chosen letter for each of the six individual categories as noted in Figure 2. I explain that the more unique the name a group devises for each individual category they receive ten points. If more than one team writes down the same name they are each awarded five points. The total amount of points any group can achieve in a single round for answering all six categories correct is sixty points. Once the students complete the first round, the process becomes iterative. The game consists of three rounds in total with the first being a practise session, and lasts a duration of five minutes. Students really enjoy this particular task because it is novel, compels them to think creatively, by focusing on unique rather than conventional names. Sometimes a letter for a particular colour can be so challenging the group resort to cheating, by attempting to google the answer. This behaviour is revealed by a lot of laughter emanating from a particular section of the room as they try consult smart phones discreetly. I adopt a humorous approach to these incidences and joke about it with them. This behaviour demonstrates their engagement and motivation to win at all costs. Once the game has ended, I encourage the same groups to select one member's research proposal, and commence brainstorming or mind mapping it in terms of keywords.

Another children's card game is "Picture This" from the makers Paladone containing magnified images of everyday objects i.e., vegetables, rope, thimbles, pasta etc. 


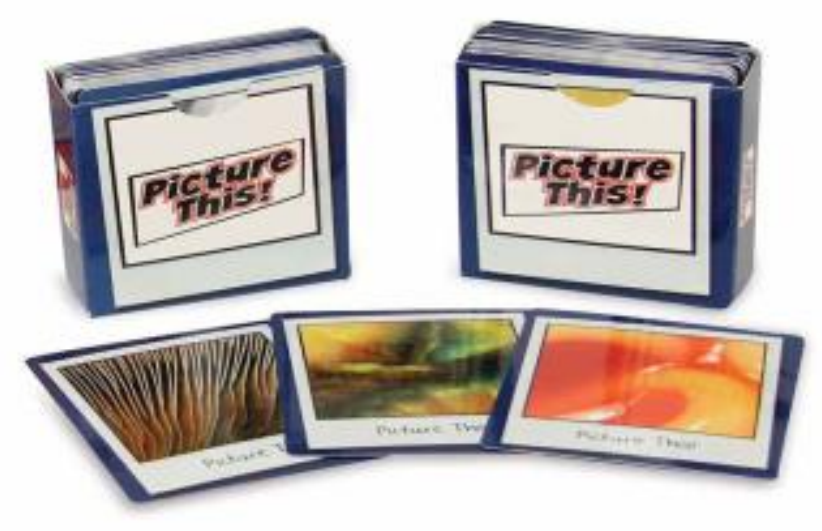

Figure 3. Picture This! Card Game

Each group receives several cards and is allocated three minutes to discuss and try identify their images. They are then subsequently probed by me for their own interpretations of these pictures, and provide an explanation for their answers. I explain that their responses are all valid because it highlights their cognitive process, before revealing the correct answer. The purpose of this particular task is to emphasise that research topics are cross disciplinary by nature and the importance of viewing them holistically rather than analytically. While reiterating the message that research must be made interesting to the reader by viewing a subject from a different perspective. The impact of these games on students' cognitive and meta-cognitive abilities is evident in the transformative learning which occurs in the days proceeding the session. In subsequent individual consultations with me to discuss their research, several students mentioned how these games provided greater clarity to the entire process. They felt confident to adopt a more innovative approach to refining their own topic from a fresh perspective. As previously discussed these newly acquired transferable skills align both with institutional objectives and will benefit them in a future work environment.

\section{Affirming and Consolidating Creativity}

Reflective Practise is an integral part of the development process for teachers as it involves critically re assessing a situation or event from a different perspective. In contrast "Transformative Learning" occurs when these individual experiences are shared with colleagues through discussions and critically reflected upon, leading to new levels of understanding (Cranton \& King 2003). This moment of elucidation compels an individual to re assess and question everything they already know. Accepting the other person's "Superior Knowledge" as the standard to which we assess our own thoughts and deeds becomes more fulfilling for us. (Polanyi, 1958)

Reflecting on my own teaching it is very much aligned with the common themes of the Social Constructivist models of learning as discussed by Anderson and Dron, (2010) in a distance education context, which is beyond the remit of this paper. My role within these workshops is one of a facilitator by ensuring they are student centred, accommodate various learning styles and conducive to a collaborative learning 
environment. Which concurs with the findings of a study conducted into US police training techniques viewed through an Andragogy lens (Birzer, 2003).

The William and Flora Hewlett Foundation (2015), defines deeper learning in terms of a student possessing the following core skills:

- Mastery of core academic content

- Critical thinking and problem solving

- Collaboration

- Effective Communication

- Self-Directed learning (view setbacks as opportunities)

- An Academic Mind set (Strong belief in themselves)

Analysing the outcomes of my own active workshops in terms of these competences ensures participants are engaged by undertaking discovery tasks and evolve into self-directed learners. As previously discussed the European Union report on the quality of teaching and learning in Higher Education (McAleese, 2013) recommends that a good teacher should be familiar with adult learning theory, self-directed learning and self-efficacy - and be able to incorporate these in their practise where appropriate. Authenticity is another quality of an effective teacher preventing him/ her from hiding behind a persona to communicate with their class, which is a barrier to the learning. Another trait is passion which is conveyed to students by inspiring them to be intellectually curious about their environment by approaching topics differently.

Reflecting on my own teaching in more detail reveals, it's a combination of both Andragogy Malcolm Knowles (1980), and Transformative Learning theory Jack Mezirow (1991),

- Create a climate of co-operation.

- Help learners identify their needs and set goals

- Present learning as tasks to be undertaken or problems solved

- Use experience of learners as a teaching resource

- Recognise initial and on-going learner needs.

- Encourage learners in examining their own assumptions of a topic.

- Provide opportunities for self-directed learning

- Justify the relevance of what is being thought.

The intended purpose is stimulate the student's intellectual curiosity, which makes them self-motivated, resulting in them becoming immersed in their topic at a deeper level. I use a post assessment instrument (Reilly, 2015), to encourage students to reflect on their learning. A synopsis of the student feedback from various sessions reveals they were most engaged when collaborating in groups, playing games and when asked about their own individual topic. 


\section{Summary and conclusion}

The literature on creativity is extensive but this research has discussed it primarily in terms of an educational context. The purpose of integrating creativity within these sessions are to engage students by encouraging them to think differently about their own research topic.

This paper has discussed several creative and innovative teaching strategies developed over the course of delivering research methods workshops to Graduate Business students to engage them.

- Encompassing a variety of both visual and text based resources appeals to multi intelligences within a group ensuring deeper learning.

- Explored relevant learning theory from a cognitive psychology perspective.

- Examined how an individual student's personal learning style evolves.

- Discussed recent education policy reports which emphasise the importance of creativity being a core skill to succeed in the future work environment.

- Mentioned the skills employers require from new recruits, and whether these Graduate skills meet labour market demands.

- Recognised that organizations which encouraged a collaborative culture provided a suitable environment for innovation and creativity to thrive. Interpreting creativity from a theoretical perspective reveals it is composed of many forms and applicable to any subject field.

- It's an effective tool to encourage engagement, innovation, and intellectual curiosity which all leads to deeper learning.

- Ultimately creativity is concerned with possessing a comprehensive knowledge of a discipline prior to recognising something is wrong within it. Being sufficiently motivated to take a risk, which may lead to new discoveries, and opportunities.

- Creative individuals perform better, are more skilful and innovative when operating within clearly defined boundaries.

- Placing a time limit of several minutes for completing each task, serves the purpose of being cognitively challenging, encourages play, and compels them to consider each potential idea as being worthwhile.

\section{References}

Adams, T. (2015). And the Pulitzer goes to... a computer. The Observer, pp. 18-19. Retrieved from http://www.theguardian.com/technology/2015/jun/28/computerwriting-journalism-artificial-intelligence

Anderson, T., \& Dron, J. (2010). Three generations of distance education pedagogy.

The International Review of Research in Open and Distributed Learning.

Retrieved from http://www.irrodl.org/index.php/irrodl/article/view/890/1724

Beck, U. (1992). Risk society towards a new modernity. Newbury Park, Calif. : Sage Publications. 
Bergson, H. (1998). Creative Evolution. 1911. Trans. Arthur Mitchell. Mineola, NY: Dover.

Birzer, M. (2003). The theory of andragogy applied to police training. Policing: An International Journal of Police Strategies \& Management, 26(1), 29-42. doi:10.1108/13639510310460288

Bruner, J. S. (Jerome S. (1962). On knowing: essays for the left hand by (5th ed.). Harvard University Press.

Chua, S. (2014). Describing my personal knowledge management routines with Harold Jarche's Seek-Sense-Share framework - sacha chua : living an awesome life. Retrieved from http://sachachua.com/blog/2014/03/describing-personalknowledge-management-routines-harold-jarches-seek-sense-share-framework/

Csikszentmihalyi, M. (1990). Flow: the psychology of optimal experience. New York: Harper \& Row.

Csikszentmihalyi, M. (1996). Creativity: flow and the psychology of discovery and invention. New York: HarperCollinsPublishers.

Deverell, A., \& Moore, S. (2014). Releasing creativity in teaching and learning: the potential role of organisational legitimacy and increased dialogue. Innovations in Education and Teaching International, 51(2), 164-174. doi:10.1080/14703297.2013.771968

Global Digital Citizen Foundation. (2015). Solution Fluency. Global Digital Citizen Foundation. Retrieved from https://globaldigitalcitizen.org/21st-centuryfluencies/solution-fluency

Hensley, R. B. (2004). Curiosity and Creativity as Attributes of Information Literacy. Reference \& User Services Quarterly, 44(1), p31-36.

Jarche, H. (2014). What is your PKM routine? Harold Jarche: adapting to perpetual beta. Retrieved from http://jarche.com/2014/03/what-is-your-pkm-routine/

Johnson, L., Adams Becker, S., Cummins, M., Estrada, V., Freeman, A., \&, Ludgate, H. (2013)., \& Austin, T. T. N. M. C. (2013). NMC Horizon Report: 2013 Higher Education Edition. Austin.

Knowles, M. S. (1980). The modern practice of adult education. Fallett.

Langley, P., \& Jones, R. (1988). A computational model of scientific insight. (Sternberg $\mathrm{R}$, Ed.)The nature of creativity: Contemporary. New York: Cambridge University Press.

Leadbeater, C. (2010). Education innovation in the slums. TED Talk. Retrieved from https://www.ted.com/talks/charles_leadbeater_on_education?language=en

López, S. P. (2004). Managing knowledge: the link between culture and organizational learning. Journal of Knowlege Management, 8(6), 93-104. doi:10.1108/13673270410567657 
Martinsen, O., \& Kaufmann, G. (2000). The assimilator-explorer cognitive styles and their relationship to affective-motivational orientations and cognitive performances. In R. S. Riding (Ed.), International perspectives on individual differences (pp. 3-39). Ablex.

McAleese. (2013). Improving the quality of teaching and learning in Europe's higher education institutions Modernisation of Higher Education. Retrieved from http://ec.europa.eu/education/library/reports/modernisation_en.pdf

McClelland, D., Atkinson, J. ., Clark, R. ., \& Lowell, E. . (1953). The achievement motive, by David C. McClelland. New York: Appleton-Century-Crofts.

Mezirow, J. (1991). Transformative dimensions of adult learning. San Francisco: Jossey Bass.

Paivio, A. (1979). Imagery and verbal processes. Lawrence Erlbaum Associates.

Piirto, J. (2011). Creativity for 21st Century Skills. Rotterdam: SensePublishers. doi:10.1007/978-94-6091-463-8

Polanyi, M. (1958). Personal knowledge: Towards a post-critical philosophy. Chicago: University of Chicago Press.

Rayner, S., \& Riding, R. (1997). Towards a categorisation of cognitive styles and learning styles. Educational Psychology. doi:10.1080/0144341970170101

Reilly, P. (2015). Strategies to Ensure Deep Learning Occurs in MBA Information Literacy Workshops. Journal of Business \& Finance Librarianship, 20(3), 172188. doi:10.1080/08963568.2015.1042812

Riding, R., \& Cheema, I. (1991). Cognitive styles - an overview and integration. Educational Psychology. doi:10.1080/0144341910110301

Robinson, K. (2001). Out of our minds : learning to be creative. Oxford: John Wiley.

Runco, M. . (2004). Creativity. Annual Review of Psychology, 55(1), 657-87. doi:10.1146/annurev.psych.55.090902.141502

Runco, M., \& Chand, I. (1995). Cognition and creativity. Educational Psychology Review, 7(3), 243-267. doi:10.1007/BF02213373

Schiuma, G. (2014). Shaping creative organisational environments through the arts. In S. Bilton, \& C, Cummings (Eds.), Handbook of Management and Creativity (pp. 346-367). Cheltenham: Edward Elgar.

Sternberg, R. J. (2006). The Nature of Creativity. Creativity Research Journal, 18(1), 87-98. doi:10.1207/s15326934crj1801_10

Tharp, T. (2003). The creative habit: learn it and use it for life : a practical guide. New York: Simon \& Schuster.

Torrance, E. P. (1981). Creative teaching makes a difference. In J. C. Gowan, G. D. Demos, \& E. P. Torrance (Eds.), Creativity:its educational implications (2nd ed., pp. 99-108). Dubuque, Ia: Kendall/Hunt Publishing Company. 
Venezia, A. (2014). Innovations Designed for Deeper Learning in Higher Education. sacramento. Retrieved from

https://library.educause.edu/ /media/Files/Library/2014/8/NGI1401-pdf.pdf

William and Flora Hewlett Foundation. (2015). What is Deeper Learning? Retrieved from http://www.hewlett.org/programs/education/deeper-learning/what-deeperlearning 